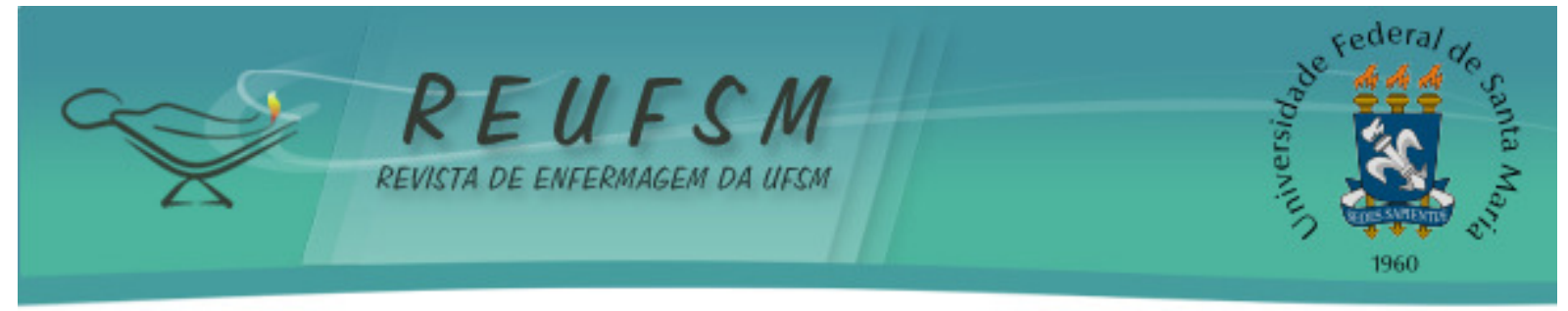

ARTIGO ORIGINAL

\title{
PERCEPÇÕES DO CUIDADO DE ENFERMAGEM À CRIANÇA HOSPITALIZADA EM CONDIÇÃO CRÔNICA
}

\section{PERCEPIONS OF NURSING CARE TO HOSPITALIZED CHILDREN IN CHRONIC CONDITION PERCEPCIONES DE LA ATENCIÓN DE ENFERMERÍA A NIÑOS HOSPITALIZADOS EN CONDICIÓN CRÔNICA}

Doi: $10.5902 / 2179769213406$

Thiago Privado da Silva ${ }^{1}$ Ítalo Rodolfo Silva ${ }^{2}$ Silvia Maria de Sá Basílio Lins ${ }^{3}$ Joséte Luzia Leite ${ }^{4}$

RESUMO: Objetivo: compreender a percepção dos profissionais de enfermagem e dos familiares sobre o cuidado de enfermagem desenvolvido à criança hospitalizada em condição crônica. Método: estudo descritivo de abordagem qualitativa desenvolvido com base nos referenciais teórico e metodológico do Pensamento Complexo e Grounded Theory, respectivamente. Os participantes do estudo totalizam 18 e estão organizados em três grupos amostrais: enfermeiros, técnicos de enfermagem e familiares. A entrevista semiestruturada foi utilizada para coleta de dados, sendo realizada entre julho e novembro de 2012. A análise dos dados seguiu as três etapas de codificação: aberta, axial e seletiva. Resultados: apresenta-se a categoria mobilizando-se para obter avanços nos cuidados de enfermagem e suas respectivas subcategorias. Conclusões: percebeu-se que o cuidado de enfermagem desenvolvido à criança hospitalizada em condição crônica apresenta aspectos positivos ressaltados pelos familiares. Todavia, carece de avanços organizacionais para sua melhor qualidade.

Descritores: Enfermagem pediátrica; Cuidados de enfermagem; Doença crônica.

ABSTRACT: Aim: to understand professionals in nursing and families' perception_about the practice of nursing care given to hospitalized children in chronic conditions. Method: descriptive qualitative study developed based on the theoretical and methodological reference Complex Thinking and Grounded Theory respectively. There were 18 participants who were organized into three sample groups: nurses, nursing technicians and family. The semi-structured interview was used to collect data, being performed between july and november 2012. The data analysis had followed three stages of coding: open, axial and selective. Results: it presents the category mobilizing to get advances in nursing care and its respectively subcategories. Conclusions: it was observed that the practice of nursing care to the hospitalized children in chronic condition shows positive

\footnotetext{
1 Enfermeiro. Mestre em Enfermagem. Doutorando em Enfermagem em Programa de Pós Graduação em Enfermagem da Escola de Enfermagem Anna Nery/EEAN/UFRJ. Rio de Janeiro - RJ. Brasil. Email: thiagopsilva87@gmail.com

2 Enfermeiro. Mestre em Enfermagem. Doutorando em Enfermagem em Programa de Pós Graduação em Enfermagem da Escola de Enfermagem Anna Nery/EEAN/UFRJ. Professor Assistente da Universidade Federal do Rio de Janeiro campus Macaé. Rio de Janeiro - RJ. Brasil. Email: enf.italo@hotmail.com

3 Enfermeira. Mestre em Enfermagem. Doutoranda em Enfermagem em Programa de Pós Graduação em Enfermagem da Escola de Enfermagem Anna Nery/EEAN/UFRJ. Rio de Janeiro - RJ. Brasil. Email: silviamarialins@gmail.com

${ }^{4}$ Enfermeira. Doutora em Enfermagem. Professora Permanente do Programa de Pós Graduação em Enfermagem da Escola de Enfermagem Anna Nery/EEAN/UFRJ. Rio de Janeiro - RJ. Brasil. Email: joluzia@gmail.com
} 


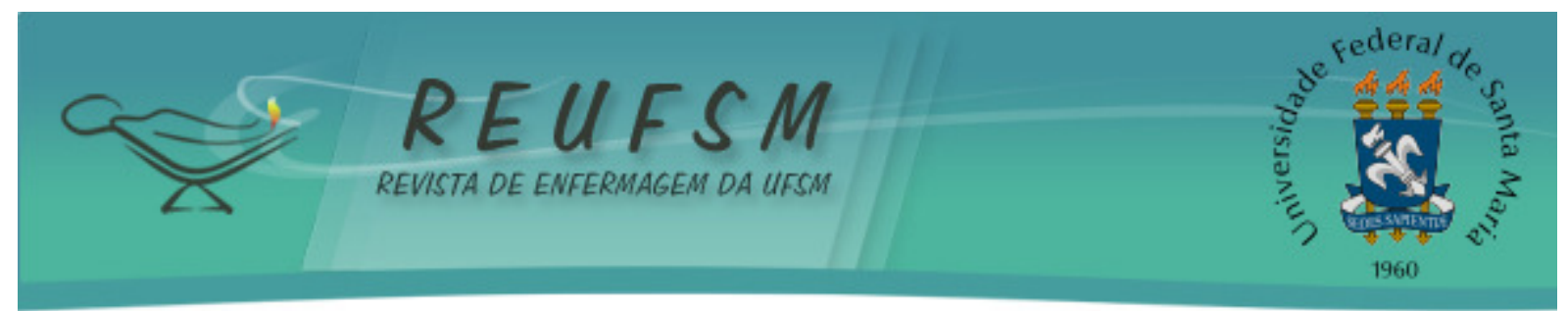

aspects mentioned by the family. However, it needs organizational advances to achieve better quality.

Descriptors: Pediatric nursing; Nursing care; Chronic disease.

RESUMEN: Objetivo: comprender la percepción de profesionales de enfermería y familiares acerca de la atención de enfermería a niños con enfermedad crónica. Método: estudio descriptivo cualitativo basado en los marcos teóricos y metodológicos, Pensamiento Complejo y Grounded Theory, respectivamente. Hubo 18 participantes en el estudio organizados en tres grupos: enfermeras, técnicos de enfermería y familia. Se utilizó la entrevista semi-estructurada, realizada entre julio y noviembre 2012, para recolección de datos. El análisis siguió tres etapas de codificación: abierta, axial y selectiva. Resultados: demuestran la categoría movilización para conseguir avances en la atención de enfermería y sus respectivas subcategorías. Conclusiones: la práctica del cuidado de enfermería al niño hospitalizado con enfermedad crónica tiene aspectos positivos mencionados por la familia. Sin embargo, carece de avances organizativos para alcanzar una mejor calidad.

Descriptores: Enfermería pediátrica; Atención de enfermería; Enfermedad crónica.

\section{INTRODUÇÃO}

Compreende-se que cuidar de uma criança hospitalizada em condição crônica implica em lidar com incertezas, dúvidas, imprevisibilidades e com a dialógica morte/vida. Nesse particular pressupõe, da equipe de enfermagem o estabelecimento de estratégias de ação/interação, a fim de garantir a continuidade e a qualidade dos cuidados realizados. ${ }^{1}$ Trata-se, portanto, de uma circunstância que insere o cuidado de enfermagem à esta clientela no contexto da complexidade, ao passo que considera o tecido de acontecimentos, ações, interações, retroações que permeiam as relações de cuidado. ${ }^{2}$

Cuidar de uma criança hospitalizada em condição crônica implica, também, em lidar com o familiar ou responsável desta, pois desde a promulgação da Lei 8.069 que regulamentou o Estatuto da Criança e do Adolescente (ECA), em 1990, assegurou-se o direito da criança e do adolescente ter um responsável que o acompanhe durante a sua hospitalização. ${ }^{3}$ Tal fenômeno tem desencadeado novas formas de organização da assistência de enfermagem cuja atenção dos profissionais deve voltar-se para as necessidades da díade criança-família. ${ }^{4}$

0 cuidado à criança hospitalizada em condição crônica solicita do enfermeiro o desenvolvimento de competências relacional, cognitiva, subjetiva e ética. ${ }^{1}$ Nessa conjuntura acrescenta-se que o familiar também se encontra envolvido nessa prática realizando cuidados de higiene corporal e administração de medicamentos por via oral. ${ }^{5}$

Admite-se que o cuidado de enfermagem à criança hospitalizada em condição crônica é um fenômeno complexo, pois se sustenta a partir de uma teia de interações estabelecidas entre o profissional, a criança e sua família; requer a elaboração de estratégias para lidar com as incertezas e com as imprevisibilidades, além disso, evoca a necessidade de um pensamento do contexto e do complexo nas relações de cuidado.

Ressalta-se que é na teia de relações humanas e interprofissionais que as percepções são produzidas e os significados são construídos, orientando as práticas de cuidado. Desse modo, objetivou-se compreender as percepções da equipe de enfermagem e dos familiares sobre o cuidado desenvolvido à criança hospitalizada em condição crônica à luz da complexidade. Para tanto, questiona-se: qual a percepção da equipe de enfermagem e dos familiares sobre o cuidado de enfermagem desenvolvido à criança hospitalizada em condição crônica? 


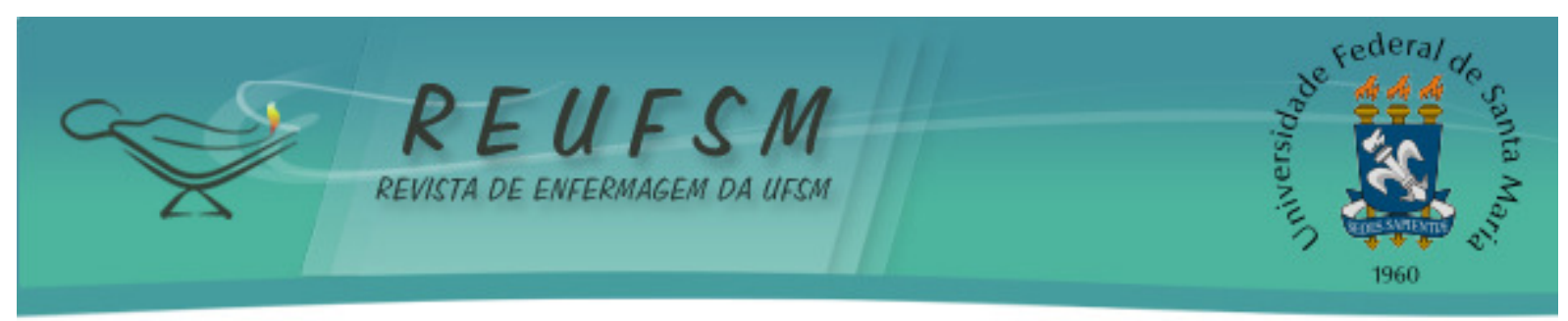

0 presente estudo parte da assertiva que compreender a percepção da equipe de enfermagem e dos familiares sobre o cuidado de enfermagem prestado à criança hospitalizada em condição crônica, possibilita conhecer os aspectos positivos e limitadores dessa prática. Com efeito, a relevância desta investigação se assenta em apresentar a perspectiva dos familiares e dos profissionais de enfermagem sobre os cuidados à criança hospitalizada em condição crônica o qual será interpretado à luz do referencial da complexidade.

Justifica-se a escolha desse referencial como possibilidade de elaborar planos de ação baseados em estratégias que favoreçam a melhoria dos cuidados prestados, considerando a ordem/desordem/interação/organização do contexto de trabalho do enfermeiro. $\mathrm{Na}$ lente da complexidade, a estratégia é o que possibilita integrar o máximo de informações e formular esquemas de ações, a fim de reunir o máximo de certeza para o enfrentamento das incertezas do mundo real. ${ }^{1}$

\section{MÉTODO}

Estudo descritivo de abordagem qualitativa ancorado nos referenciais teórico e metodológico, respectivamente, do Pensamento Complexo e a Grounded Theory (GT), em português, Teoria Fundamentada nos Dados (TFD).

A TFD é um método de pesquisa que tem sido muito utilizado na área da Enfermagem em virtude de sua contribuição na compreensão de fenômenos pouco explorados e na produção de modelos explicativos e teorias, provendo ao investigador um marco útil no estudo das relações interpessoais no ambiente de cuidado. ${ }^{6}$ Quanto ao Pensamento Complexo, trata-se de um modo de pensar a realidade que se opõe à visão unidimensional, pois a considera pobre e insuficiente para a compreensão da multidimensionalidade dos fenômenos complexos. ${ }^{2}$

Os dados foram coletados na Unidade de Internação Pediátrica (UIP) de um Hospital Federal Universitário, situado no Rio de Janeiro, Brasil, no período compreendido entre julho e novembro de 2012, por meio da entrevista semiestruturada. Trata-se de um hospital especializado em pediatria onde mais de $50 \%$ das crianças internadas possuem doenças crônicas ou raras, ou ainda, são hospitalizadas sem um diagnóstico clínico definido. $^{5}$

Seguindo os pressupostos da TFD, ${ }^{7}$ os participantes do estudo foram selecionados e organizados em três grupos amostrais, a saber: o primeiro grupo amostral foi composto por enfermeiros, o segundo grupo amostral foi constituído por técnicos de enfermagem e o terceiro e último grupo amostral foi composto por familiares. A organização dos participantes em grupos amostrais decorreu de um recurso analítico da TFD denominado amostragem teórica cujo objetivo é buscar locais, pessoas ou fatos que aumentem a possibilidade de descobrir variações entre os conceitos construídos no que refere às suas propriedades e dimensões.

Compreende-se que o enfermeiro é o profissional responsável pela organização, execução e avaliação dos serviços da assistência de enfermagem. Desse modo, inicialmente foram realizadas entrevistas com estes profissionais que atenderam os seguintes critérios de inclusão: ser enfermeiro com experiência mínima de três anos no cuidado à criança em condição crônica; estar alocado na Unidade de Internação Pediátrica; ter um ano de vinculação à instituição. Foram excluídos os enfermeiros que se encontravam de férias, em licença ou afastados do trabalho. As entrevistas com os participantes do primeiro grupo amostral foram norteadas pelas seguintes questões: como o enfermeiro desenvolve 0 cuidado à criança hospitalizada em condição crônica? Como ele percebe a assistência prestada à criança? Compuseram esse primeiro grupo amostral oito enfermeiros, sendo 


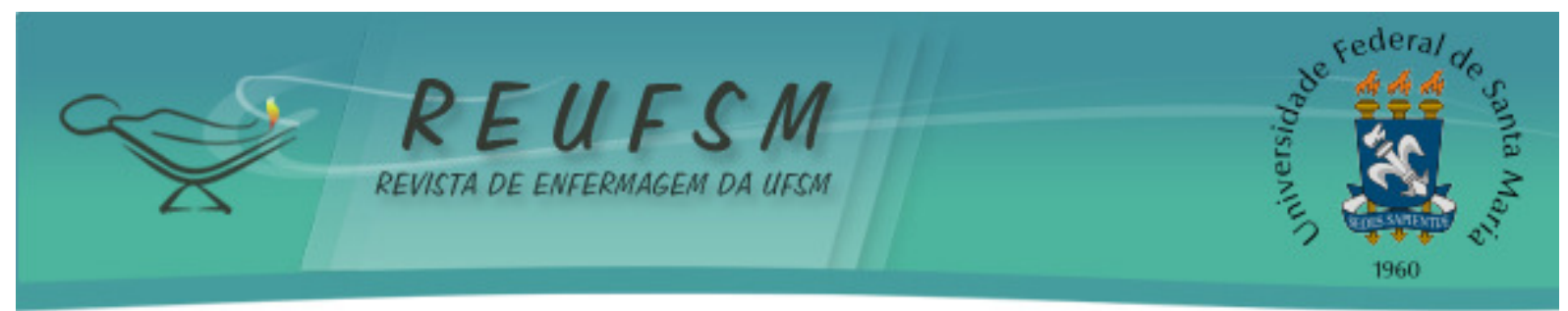

sete do sexo feminino e um do sexo masculino, com tempo de experiência no cuidado à criança em condição crônica, variando entre quatro e 32 anos.

0 tratamento analítico das entrevistas realizadas com os enfermeiros revelou que o cuidado de enfermagem à criança hospitalizada em condição crônica é desenvolvido mediante a participação/interação do enfermeiro com os técnicos de enfermagem, os quais estão envolvidos na realização dos cuidados diretos à criança. Tal circunstância direcionou a investigação para os técnicos de enfermagem, a fim de compreender sua percepção sobre o seu envolvimento no gerenciamento do cuidado. Para tanto, estes profissionais deveriam atender os mesmos critérios de inclusão e de exclusão definidos para composição do primeiro grupo amostral. As entrevistas com os técnicos de enfermagem foram realizadas apoiando-se nas questões norteadoras a seguir: como o técnico de enfermagem percebe seu envolvimento no cuidado à criança hospitalizada em condição crônica? Como ele avalia a assistência prestada à criança? Participaram desse segundo grupo amostral seis técnicos de enfermagem, todos do sexo feminino com período de experiência no cuidado à criança em condição crônica, variando entre cinco e 27 anos.

Ao apresentarem seu envolvimento no cuidado de enfermagem à criança hospitalizada em condição crônica, os técnicos de enfermagem relataram que os familiares da criança percebem o desenvolvimento dessa prática e influenciam sua operacionalização, uma vez que são legalmente responsáveis pela criança. Por essa razão, a investigação foi direcionada para os familiares das crianças hospitalizada em condição crônica, a fim de conhecer sua percepção sobre os cuidados de enfermagem. Para tanto, foi estabelecido como critério de inclusão ser familiar de uma criança hospitalizada em condição crônica na UIP. As entrevistas com os familiares foram guiadas pela questão: como os familiares percebem os cuidados de enfermagem à criança hospitalizada em condição crônica? Compuseram esse terceiro grupo amostral quatro familiares, sendo todas mães de crianças hospitalizadas em condição crônica.

Salienta-se que a finalização da coleta de dados em cada grupo amostral foi determinada pelo recurso da saturação teórica, no qual os novos dados coletados já não estavam alterando em consistência e densidade teórica os conceitos construídos. ${ }^{7}$

$\mathrm{Na}$ TFD, os dados são coletados e concomitantemente analisados. A análise comparativa dos dados seguiu as seguintes etapas de codificação: aberta, axial e seletiva. $\mathrm{Na}$ codificação aberta, os dados foram codificados linha por linha, gerando os códigos preliminares que, por sua vez, após serem agrupados por similaridades, deram origem aos códigos conceituais. 0 agrupamento dos códigos conceituais por similaridades originaram as categorias e as subcategorias. Na codificação axial, as categorias foram relacionadas entre si e entre suas subcategorias, a fim de definir suas propriedades e dimensões. Nesse momento da análise, foi utilizada uma ferramenta analítica denominada de paradigma. Esta, permite a integração da estrutura e processo do fenômeno investigado. Compreendese como estrutura, as condições causais, contextuais e intervenientes, e processo, as estratégias de ação/interação e as consequências. Na codificação seletiva, foi determinada a categoria central do estudo. Aliado ao processo de codificação, foram elaborados memorandos e diagramas que auxiliaram o investigador na análise teórica dos dados. ${ }^{7}$

A categoria Mobilizando-se para obter avanços nos cuidados de enfermagem e suas respectivas subcategorias emergiram da análise dos dados como consequência do fenômeno Estabelecendo relações e interações para o gerenciamento do cuidado de enfermagem à criança com condição crônica hospitalizada na Unidade de Internação Pediátrica. Dada a sua relevância e peculiaridade em apresentar os aspectos positivos e as limitações do cuidado de enfermagem prestado à criança hospitalizada em condição crônica, optou-se por apresentá-la separadamente neste artigo. 


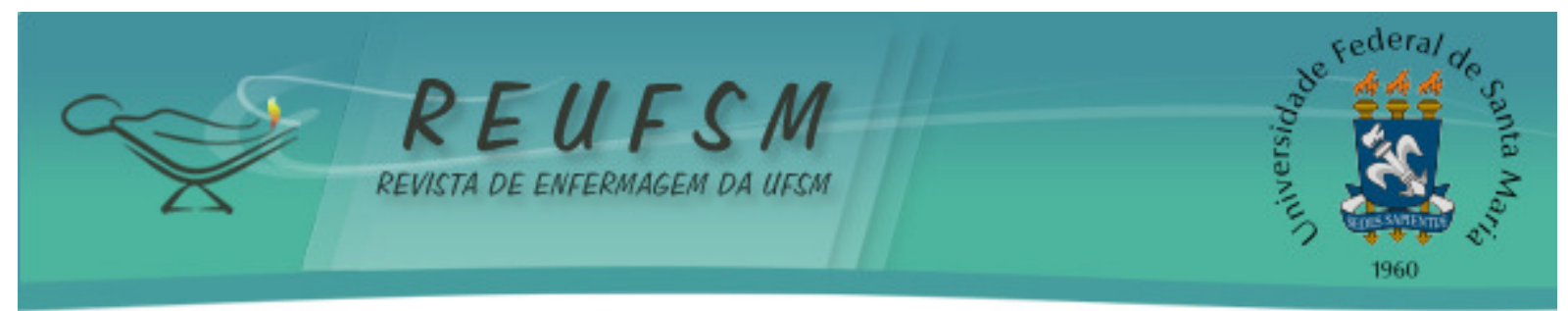

Atendendo as recomendações da Resolução 466/12 do Conselho Nacional de Saúde do Ministério da Saúde, a coleta de dados somente foi iniciada após aprovação do estudo pelo Comitê de Ética em Pesquisa da Escola de Enfermagem Anna Nery - EEAN/HESFA/UFRJ, sob parecer de número 8921, e pelo Comitê de Ética em Pesquisa do Hospital Federal Universitário onde o estudo foi realizado, sob parecer de número 07/12. Aos participantes do estudo, foi solicitada a assinatura do Termo de Consentimento Livre e Esclarecido (TCLE). Para garantir o anonimato destes, as falas dos enfermeiros foram identificadas pela letra $E$, as dos técnicos de enfermagem pela letra $T$ e as dos familiares pela letra $F$. Todas estão seguidas por um algarismo de acordo com a ordem das entrevistas de cada grupo amostral (E1, T1, F1).

\section{RESULTADOS E DISCUSSÃO}

A categoria Mobilizando-se para obter avanços nos cuidados de enfermagem é constituída pelas seguintes subcategorias: Vislumbrando melhorias nos cuidados de enfermagem e Perspectiva do familiar acerca do cuidado de enfermagem à criança hospitalizada em condição crônica.

Vislumbrando melhorias no cuidado de enfermagem como subcategoria apresenta a perspectiva dos profissionais de enfermagem sobre os cuidados desenvolvidos à criança hospitalizada em condição crônica. Nesse sentido, eles perceberam sua prática como limitada ao reconhecer que nem sempre é possível atender as múltiplas necessidades da criança e do seu familiar.

Nem sempre dá para fazer exatamente aquilo que deveria ser feito, $a$ gente não tem condição de atender algumas necessidades $e$, às vezes, a assistência que eu dou para a criança é a que no momento ela não está precisando. (E1)

Às vezes, a gente não atende aquela necessidade da criança ou do acompanhante ou do próprio serviço da equipe, então, nesse sentido, percebemos que não estamos conseguindo prestar uma assistência legal e isso gera estresse para a gente. (E3)

Ao reconhecer as limitações dos cuidados de enfermagem, o participante E3 referiu vivenciar estresse, sendo este um fator que influencia a produtividade profissional. Sob esta perspectiva, a literatura ${ }^{8}$ registra que a forte carga psicoemocional decorrente da relação enfermeiro - paciente, as exigências físicas, o déficit de trabalhadores, os turnos prolongados e as condições inadequadas de trabalho contribuem e exacerbam experiências estressantes no trabalho da enfermagem favorecendo o surgimento de doenças.

Em outro estudo, ${ }^{9}$ foi revelado que as situações percebidas como estressantes para os enfermeiros entrevistados estão relacionadas ao ambiente físico da unidade de trabalho, aos aspectos relacionais do processo de trabalho da enfermagem, ao processo saúdedoença dos pacientes e à organização do processo de trabalho na instituição de saúde. Considera-se, portanto, o estresse profissional como fator interveniente da qualidade da assistência de enfermagem.

Ao refletir sobre o cuidado de enfermagem desenvolvido ao grupo de crianças em estudo, o profissional abaixo reconheceu a necessidade de mais empenho para a melhoria da prática.

Eu acho que a assistência de enfermagem não é das melhores, eu acho que eu poderia ser melhor, dar um pouco mais de mim. (T1) 


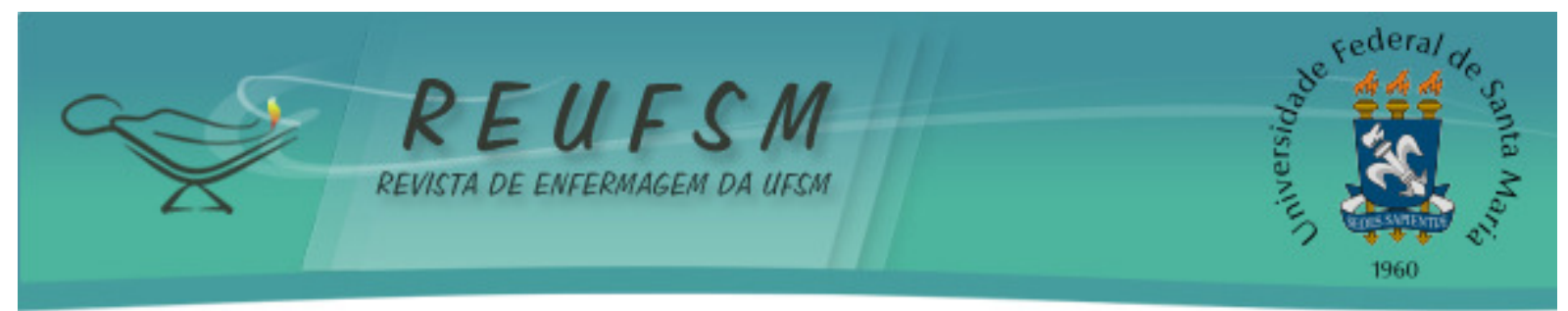

Em contrapartida, outros profissionais manifestaram um sentimento de satisfação no que tange à assistência de enfermagem prestada à criança e aos seus familiares. Tal circunstância decorre das retroações que emergem de suas relações no trabalho em equipe e no cuidado à criança e ao seu familiar.

Acho que tem sido satisfatório, a gente ver isso tanto em relação a nossa chefia, nossos colegas e pacientes. Por exemplo, cheguei aqui e foi uma festa, então eu acho que, na medida do possível, eu tenho conseguido cumprir o meu trabalho. (T3)

Eu me dou nota 10 porque eu sou dedicada e aquilo que eu não sei eu estou sempre procurando saber. Eu costumo receber elogios não só de colegas enfermeiros, mas da mãe e isso é bom. (T5)

Em uma revisão integrativa ${ }^{10}$ sobre a satisfação profissional no trabalho da equipe de enfermagem, apresentaram-se como fatores de satisfação: o gostar do que faz, a inserção em uma proposta inovadora, a qualidade dos serviços prestados, o apoio espiritual, o relacionamento no trabalho e o reconhecimento pelo trabalho realizado.

A satisfação no trabalho em saúde é compreendida como uma reação afetiva do empregado ao seu trabalho, com base na comparação entre os resultados reais com os resultados desejados, sendo uma condição que favorece a motivação e a produtividade profissional estimulando o atendimento de alta qualidade aos pacientes. ${ }^{11}$

Destaca-se, portanto, que as retroações influenciam os comportamentos dos participantes nas relações de cuidados ao passo que apresentam às respostas/re-ações do outro às atitudes desenvolvidas. Tal fenômeno promove a auto-organização que na perspectiva da complexidade evoca o princípio da recursividade, no qual a causa age sobre o efeito e o efeito retroage sobre a causa. ${ }^{1}$ A noção de recursividade ressalta a ideia de não linearidade da realidade complexa e se aplica nas relações de cuidado quando os profissionais se auto-organizam para lidar com as incertezas e com as imprevisibilidades que emergem de suas interações. Nesse particular, as retroações surgem em forma de elogios como registrado na fala anterior ou por meio de atitudes de carinho como acontecem nas relações entre o profissional e a criança, conforme consta na fala do profissional a seguir:

quando eu chego ou quando eu encontro eles [crianças] nos corredores, eles lembram de mim, me chamam pelo meu nome, me abraçam, me beijam e é gratificante isso. As mães falarem bem de você nas reuniões, às vezes os enfermeiros comentam que as mães falaram que gostaram do seu trabalho, como você lida com a criança. (T4)

Compreende-se, portanto, que as retroações retroalimentam as relações de cuidado e as influenciam (des)motivando os processos interativos que sustentam a prática. Enquanto facilitadora da auto-organização dos sistemas vivos, organizações e processos relacionais e interativos, elas conferem dinamicidade aos fenômenos complexos ${ }^{12}$ motivando a (re)elaboração de estratégias de ação/interação para o seguimento e efetividade dos cuidados implementados.

Admitiu-se a necessidade de uma abordagem maior com os familiares das crianças, haja vista sua longa permanência e importante participação no processo de hospitalização da criança. 


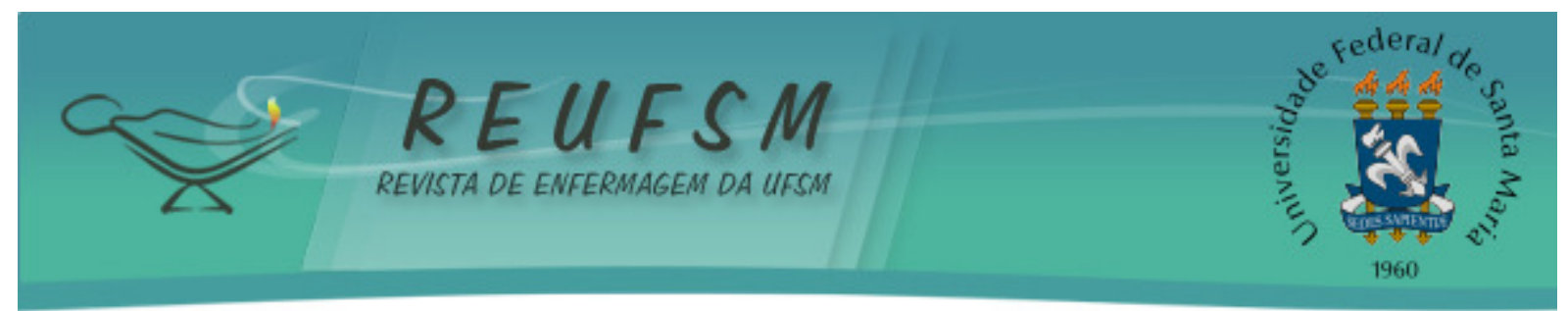

Acho que aqui precisaria de um trabalho maior com os acompanhantes, aqui a gente precisa dessa abordagem maior, a gente convive muito próximo, eles convivem muito tempo aqui dentro. (E8)

Com base na fala anterior salienta-se a necessidade de investimento na relação com o familiar, a fim de estabelecer uma efetiva interação entre o profissional e o mesmo. ${ }^{13}$ Acerca da importância do familiar na hospitalização da criança, estudos ${ }^{4,14}$ revelam que ele age como mediador da relação equipe-criança, sendo a fonte primária de confiança, segurança e carinho desta ultima. Nessa direção, entende-se a família como um espaço de complexidade humana no qual se concentram os cuidados à criança. ${ }^{12}$ Desse modo, cabe à Enfermagem valorizar a família como copartícipe, pois ela tem algo a dizer e a fazer nas relações de cuidado. ${ }^{15}$

0 esforço dos profissionais em oferecer à criança hospitalizada em condição crônica um cuidado de qualidade é expresso nas falas que seguem que também ressaltam o comprometimento e a dedicação destes nas relações de cuidado à criança hospitalizada.

Normalmente, o pessoal daqui é muito comprometido, dedicado, eles têm um perfil de cuidado muito legal. (E3)

A gente percebe que o grande trunfo da instituição são as pessoas que trabalham aqui porque se você observar lá fora você vê exemplos ruins, e os profissionais daqui são muito dedicados, os profissionais daqui dão conta, fazem muita coisa que eu acho difícil encontrar por aí. (E8)

Perspectiva do familiar acerca do cuidado de enfermagem à criança hospitalizada em condição crônica é a subcategoria que apresenta a percepção dos familiares sobre a assistência de enfermagem à clientela investigada. A este respeito os familiares manifestaram um sentimento de satisfação com a assistência de enfermagem prestada à criança e destacaram a solicitude e a atenção dos profissionais nas relações com a criança.

Eles cumprem o papel deles, talvez eles prestam mais atenção nas nossas crianças que a gente mesmo que está ali do lado, eles são muito atenciosos, todos eles aqui [...] para mim são todos muito maravilhosos. (F1)

Eu não tenho o que reclamar, eu estou bem satisfeita [...] eles estão sempre perguntando o que a criança está sentindo. (F2)

A equipe, aqui, graças a Deus está sendo ótima! Até agora eu ainda não encontrei nenhuma dificuldade em relação aos cuidados. (F3)

Aqui nessa enfermaria é boa, eu gostei, elas são bem atenciosas, a equipe é boa e não tenho nada que reclamar. (F4)

Os familiares ressaltaram o carinho e a paciência como elementos necessários para o cuidado à criança hospitalizada em condição crônica.

Você tem que ter paciência para poder chegar perto deles [crianças] e fazer os cuidados necessários, tem que ser feito sempre com bastante carinho. (F2) 


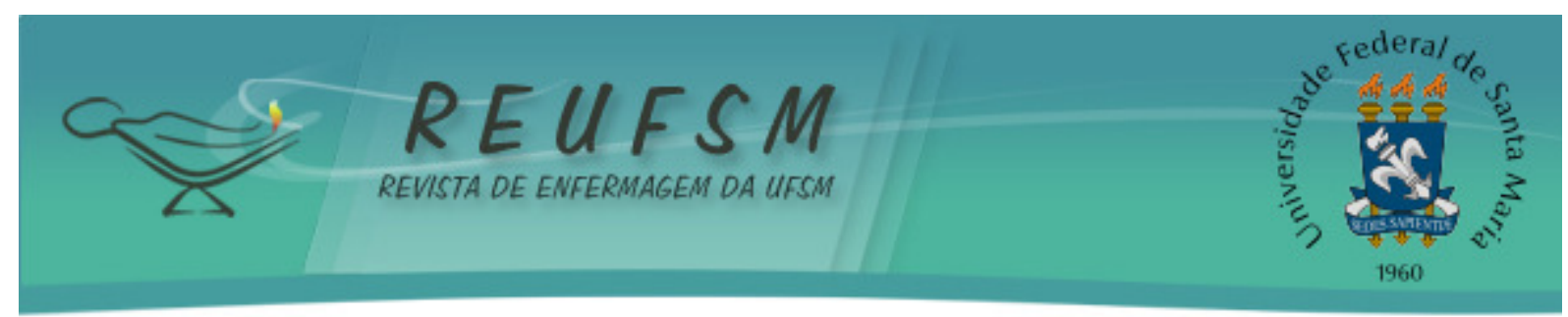

Aqui, graças a Deus a equipe que está cuidando do meu filho está sendo muito boa, ele está sendo bem tratado, eles são muito carinhosos. (F3)

Carinho, atenção, solicitude e paciência evocam a importância da afetividade nas relações de cuidado. Esta, permite a comunicação cordial nas relações interpessoais, a simpatia e a projeção/identificação com outro produzindo compreensão e conivência. ${ }^{12}$ Todavia, estudo ${ }^{16}$ realizado com mães de crianças em Unidade de Terapia Intensiva revelou que para estas, além de carinho, atenção e solicitude é importante que os profissionais detenham o conhecimento técnico-científico para a realização dos cuidados de enfermagem. Nesse sentido foi lembrado por um familiar a qualificação do profissional para a realização dos cuidados.

Todos eles são muito bem preparados, muito bem treinados, meu filho faz tratamento aqui desde 2008 e eu nunca vi nenhum enfermeiro aqui errar, pode até existir porque errar é humano, mas não vi nessa equipe deste hospital. (F1)

A perspectiva de $\mathrm{F} 1$ sobre erro humano evoca a ideia de que o mundo real e a vida real são complexos e, desse modo, incluem certo nível de erro, incerteza e ilusão. 0 erro pode ser compreendido como desacerto, a incerteza como dúvida e a ilusão como percepção distorcida do fenômeno. Negar a existência desses elementos implica em negar a nossa própria existência no mundo. É preciso, portanto, aprender a lidar com o erro, a incerteza e a ilusão. Em especial, aprender a lidar com o autoengano que surge quando se nega a existência de tais elementos. ${ }^{17}$

Um familiar percebeu diferença no desempenho dos trabalhadores da equipe de enfermagem dos serviços noturno e diurno. Sob essa perspectiva, segue a fala:

a parte da manhã eu acho bem melhor, acho que a noite o pessoal já está vindo de outro plantão, não é que não dar aquele tratamento, mas eu acho que de manhã tem mais aquele gás que o pessoal da noite. Então assim de manhã o pessoal é mil e de noite o pessoal é novecentos. (F3)

De fato, trabalhar no sentido inverso ao funcionamento fisiológico do organismo pode levar a alterações no desempenho das atividades com consequências prejudiciais para a segurança dos trabalhadores. ${ }^{18}$ Por essa razão, estudo ${ }^{19}$ faz um alerta para a presença de alto nível de estresse em trabalhadores de enfermagem do serviço noturno. Nesse sentido compreende-se que o serviço noturno gera impactos na saúde e na relação social dos trabalhadores de enfermagem. ${ }^{20}$

Quando questionados em quais aspectos a equipe de enfermagem precisava melhorar para o cuidado da criança, os familiares responderam:

eu não consigo ver o que falta, porque eu não vejo faltar, eles são completos, os enfermeiros são maravilhosos. (F1)

eu não tenho nada a reclamar do trabalho da equipe, para mim eles são ótimos. (F2)

até agora, para mim está tudo bem. (F3) 


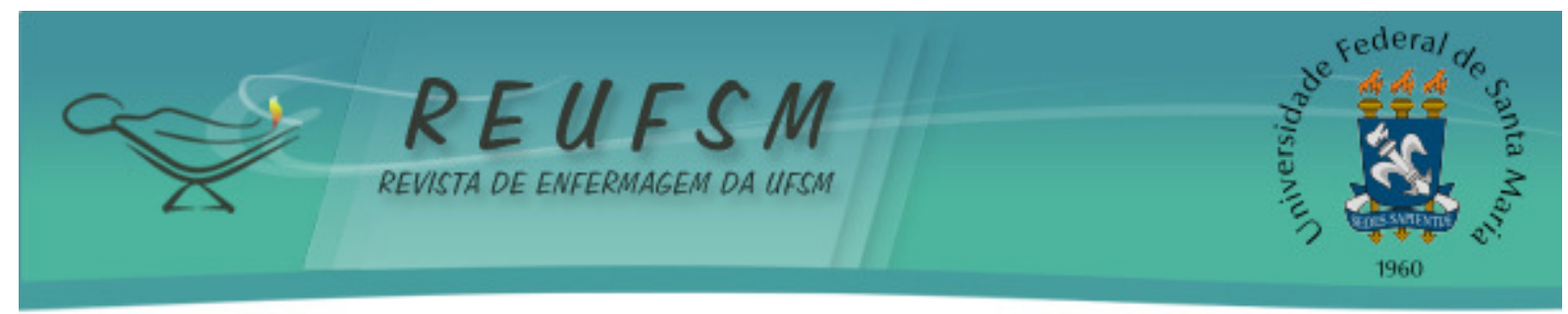

aqui não precisa melhorar nada, não falta nada, eles são ótimos. (F4)

Assim, compreendeu-se que os familiares reconhecem e valorizam o trabalho da equipe de enfermagem no cuidado à criança hospitalizada em condição crônica. Ademais, as falas sinalizam a satisfação dos familiares aos cuidados profissionais desenvolvidos à criança.

\section{CONCLUSÕES}

Mobilizando-se para obter avanços nos cuidados de enfermagem possibilitou compreender que o cuidado desenvolvido à criança hospitalizada em condição crônica comporta sentimentos de carinho, atenção, solicitude e paciência percebidos pelos familiares como necessários nas relações de cuidado. Ademais, apresentou limitações da prática de cuidados relacionadas ao não atendimento de algumas demandas da díade criança/família e a necessidade de investimentos na abordagem ao familiar da criança.

A categoria considerou o estresse profissional como fator interveniente das relações de cuidado que na situação apresentada decorreu da impossibilidade do profissional atender algumas demandas da díade. Foi ressaltado a necessidade de conhecimento técnico-científico para o cuidado desta criança. Os familiares perceberam uma diferença no desempenho dos trabalhadores de enfermagem dos serviços diurno e noturno.

Embora os familiares estejam satisfeitos com a assistência prestada à criança hospitalizada em condição crônica, os resultados do presente estudo sugerem a necessidade de uma reorganização das práticas de cuidado com a finalidade de atender demandas da criança, da família e dos profissionais de enfermagem. Outrossim, sugerem novos estudos que deem voz à criança hospitalizada em condição crônica para a compreensão de suas percepções sobre os cuidados recebidos da equipe de enfermagem, visando possíveis elaborações e implementações de novas abordagens de cuidados.

\section{REFERÊNCIAS}

1. Silva TP, Santos MH, Sousa FGM, Cunha CLF, Silva IR, Barbosa DC. Cuidado do enfermeiro à criança com condição crônica: revelando significados. Cienc Cuid Saude. 2012 abr/jun;11(2):376-83.

2. Morin E. Introdução ao pensamento complexo. $5^{\mathrm{a}}$ ed. Lisboa (PT): Instituto Piaget; 2008.

3. Brasil. Presidência da República. Lei 8.069, de 13 de julho de 1990. Dispõe sobre o Estatuto da Criança e do Adolescente. Rio de Janeiro (RJ): ALERJ; 2004.

4. Lima AS, Silva VKBA, Collet N, Reichert APS, Oliveira BRG. Relações estabelecidas pelas enfermeiras com a família durante a hospitalização infantil. Texto \& Contexto Enferm. 2010 out-dez;19(4):700-8.

5. Sousa TV, Oliveira ICS. Interação familiar/acompanhante e equipe de enfermagem no cuidado à criança hospitalizada: perspectivas para enfermagem pediátrica. Esc Anna Nery Rev Enferm. 2010 jul-set;14(3):551-9.

6. Leite JL, Silva LJ, Oliveira RMP, Stipp MAC. Thoughts regarding researchers utilizing Grounded Theory. Rev Esc Enferm USP. 2012 jun;46(3):772-7.

7. Strauss AL, Corbin J. Pesquisa qualitativa: técnicas e procedimentos para 0 desenvolvimento da teoria fundamentada. Porto Alegre: Artmed; 2008.

8. Magnago TSBS, Lisboa MTL, Griep RH. Estresse, aspectos psicossociais do trabalho e distúrbios musculoesqueléticos em trabalhadores de enfermagem. Rev Enferm UERJ 


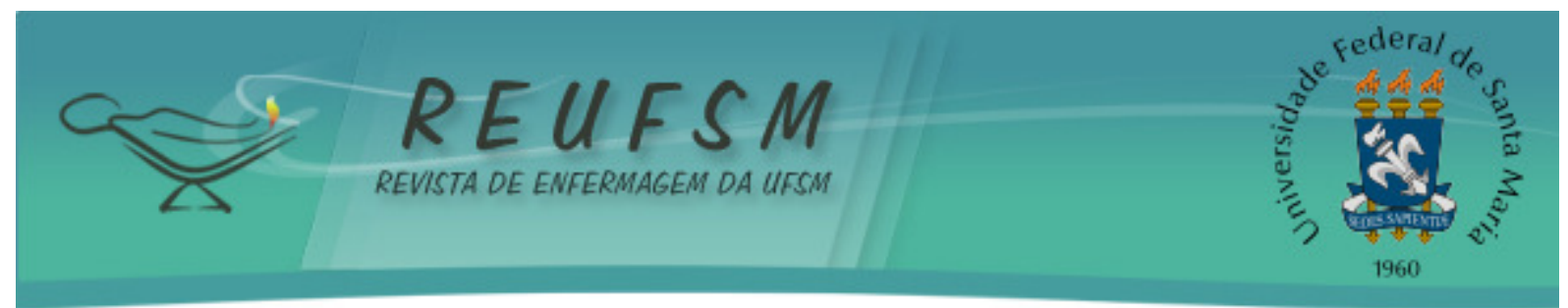

[Internet]. 2009 jan/mar [acesso em 2014 mar 9];17(1):118-23. Disponível em: http://www.facenf.uerj.br/v17n1/v17n1a22.pdf.

9. Lima GF, Bianchi ERF. Estresse entre enfermeiros hospitalares e a relação com as variáveis sociodemográficas. Rev Min Enferm. 2010;14(2):210-8.

10. Melo MB, Barbosa MA, Souza PR. Satisfação no trabalho da equipe de enfermagem: revisão integrativa. Rev Latinoam Enferm. 2011;19(4):1047-55.

11. Klopper HC, Coetzee SK, Pretorius R, Bester P. Practice environment, job satisfaction and burnout of critical care nurses in South Africa. J Nurs Manag. 2012;20(5):685-95.

12. Morin E. O método 5: a humanidade da humanidade. 5a ed. Porto Alegre (RS): Sulina; 2012.

13. Rangel RF, Backes DS, Siqueira DF, Moreschi C, Piexak DR, Freitas PH, et al. Interação profissional - usuário: apreensão do ser humano como ser singular e multidimensional. Rev Enferm UFSM [Internet]. 2011 jan-abr [acesso em 2014 jan 9]:1(1):22-30. Disponível em: http://cascavel.ufsm.br/revistas/ojs-2.2.2/index.php/reufsm/article/view/2086.

14. Quirino DD, Collet N, Neves AFGB. Hospitalização infantil: concepções da enfermagem acerca da mãe acompanhante. Rev Gaúcha Enferm. 2010 jun;31(2):300-6.

15. Collet $N$. Sujeitos em interação no cuidado à criança hospitalizada: desafios para a enfermagem pediátrica. Rev Bras Enferm. 2012;65(1):7-8.

16. Morais GSN, Costa SFG. Experiência existencial de mães de crianças hospitalizadas em Unidade de Terapia Intensiva. Rev Esc Enferm USP. 2009;43(3):639-46.

17. Mariotti H. Pensando diferente: como lidar com a complexidade, a incerteza e a ilusão. São Paulo: Atlas; 2010.

18. Lisboa MTL, Oliveira MM, Reis LD. O trabalho noturno e a prática de enfermagem: uma percepção dos estudantes de enfermagem. Esc Anna Nery R Enferm. 2006;10(3):393-8.

19. Karla MB, Ferraz Bianchi ER. La relación estrés, resistencia y turno de trabajo en enfermeros de un hospital de enseñanza. Enferm Global [Internet]. 2013 jan [acesso em 2014 mar 9];12(29):274-80. Disponível em: http://scielo.isciii.es/scielo.php?pid=S169561412013000100014 \&script=sci_arttext.

20. Silva RM, Beck CLC, Magnago TSBS, Carmagnani MIS, Tavares JP, Prestes FC. Trabalho noturno e a repercussão na saúde dos enfermeiros. Esc Anna Nery Rev Enferm. $2011 ; 15(2): 270-6$.

Data de recebimento: 03/04/2014

Data de aceite: 01/06/2015

Contato com autor responsável: Thiago Privado da Silva

Endereço postal: Rua Afonso Cavalcanti, 275, Cidade Nova, Rio de Janeiro - RJ.

E-mail: thiagopsilva87@gmail.com 